\title{
Combined Patients and Medical Related Cosmetic Breast Cancer Outcomes-A Preferred Approach to Outcomes Assessment
}

\author{
Michael Sugrue 1,2*, Alison Johnston 1,2, Amy Degnim³, Isabel T. Rubio4, M. Petrouska Van den Tol5, \\ Risal Djohan6, Mark Valentine ${ }^{1,2}$, Geraldine Mac Gregor ${ }^{1,2}$
}

${ }^{1}$ Breast Centre North West, Letterkenny University Hospital, Donegal, Ireland

${ }^{2}$ Donegal Clinical Research Academy, Donegal, Ireland

${ }^{3}$ Mayo Clinic, Rochester, NY, USA

${ }^{4}$ Vall d'Hebron Hospital Universitario, Barcelona, Spain

${ }^{5}$ University Medical Centre, Amsterdam, Netherlands

${ }^{6}$ University Medical Centre, Amsterdam, Netherlands

Email: *michael.sugrue@hse.ie

How to cite this paper: Sugrue, M., Johnston, A., Degnim, A., Rubio, I.T., Van den Tol, M.P., Djohan, R., Valentine, M. and Gregor, G.M. (2019) Combined Patients and Medical Related Cosmetic Breast Cancer Outcomes-A Preferred Approach to Outcomes Assessment. Advances in Breast Cancer Research, 8, 31-44. https://doi.org/10.4236/abcr.2019.81003

Received: October 31, 2018

Accepted: December 22, 2018

Published: December 25, 2018

Copyright $\odot 2019$ by authors and Scientific Research Publishing Inc. This work is licensed under the Creative Commons Attribution International License (CC BY 4.0).

http://creativecommons.org/licenses/by/4.0/ cC) (7) Open Access

\begin{abstract}
Introduction: Reducing positive margins and need for re-excision yet maintaining cosmesis is key in breast cancer surgery. This study describes the evaluation of early outcomes of a combined cosmetic assessment programme following breast conservation surgery (BCS). Methods: An ethically approved prospective study was conducted at Letterkenny University Hospital and a 15-month timeframe was chosen. All consecutive patients undergoing conservative breast surgery with complete local excision, from July 2015 to October 2016, were entered into the study. Patients undergoing mastectomy and reconstruction with either implant or autologous tissue were not included. 41 patients undergoing BCS were analysed. Objective and subjective cosmetic evaluations were carried out. Assessments used were the Breast Cancer Conservative Treatment-cosmetic results [BCCT.core 2.0] Software, a panel of 4 experts in breast surgery and the Breast Cancer Treatment Outcome Scale (BCTOS). Demographic and pathological data, breast excision weight, $\%$ breast volume excised (BVE), margin positivity, complications and re-excision were documented. Data was expressed as mean and standard deviation for normally distributed data and medians and inter quartile range for non-normal data. Scores were also dichotomised to excellent/good and fair/poor and results were analysed. Results: 41 patients' mean age is $55 \pm 13$ years. Mean breast volume was $768.3 \mathrm{~cm}^{3} \pm 440$; BVE weighed $78.6 \mathrm{~g} \pm 42.6$ $(18.9-214.4)$ and $\%$ BVE $11.3 \% \pm 5.2 \%(5.1-23.3)$. Re-excision rate was $2 / 41$ (4.9\%) all for positive margins. $0 / 41$ infections or haematomas occurred.
\end{abstract}


Cosmetic status of 10 - 14 days post surgery was excellent or good by BCCT.core Software 78\%, Expert panel 82.9\%, BCTOS scale (92.7\%), and fair or poor in $22 \%, 17.1 \%$ and $7.3 \%$ respectively. Conclusion: This study successfully evaluated objective and subjective cosmetic related outcomes following breast conserving surgery, incorporating both patient and surgeon in these assessments. The encouraging results show that despite low re-excision rates, acceptable cosmetic outcomes were achieved.

\section{Keywords}

Breast Cancer, Breast Conserving Surgery, Cosmetic Outcome, Cosmetic Assessment

\section{Introduction}

Increasingly health care is recognising the need to understand patients' perceptions of their treatment [1] [2]. Evaluation of breast cancer care outcomes should reflect the many disciplines involved in patients' care. Patient related cosmetic outcomes following breast cancer surgery is increasingly being reported as an integral part of patient satisfaction reported outcome. While it is patients actual outcomes that are key, incorporation of health care providers' assessment of outcome in a combined approach may add benefit.

Breast conserving surgery (BCS) remains the cornerstone to breast cancer surgery accounting for more than $60 \%$ of all surgeries [3]. When combined with radiotherapy, it provides equal or even higher survival benefits as mastectomy as long as margins are clear of tumour [4] [5] [6] [7].

Obtaining a clear margin, free of tumour and with the smallest excision volume is important for cosmetic outcomes [8] [9]. The reported re-excision rates following BCS average $20 \%$ range from $3.4 \%$ to $43.9 \%$ [10] [11]. Letterkenny University Hospital's re-excision rate in conservative breast cancer is $8 \%$ [12]. Re-excision rates should balance oncological, functional and cosmetic outcomes. A single index operation is ideal, potentially reducing complications and enhancing oncological outcomes [13], and should not remove excessive normal breast. This will avoid breast distortion while maintaining favourable cosmetic and functional outcomes [9] [14] [15] [16]. There have been recent attempts to look at standardising cosmetic evaluation [17].

While oncological outcomes are reported widely by overall survival rates, cosmetic and functional outcomes are underreported [18]. A key question remains whether low margin positivity and subsequent low re-excision rates come with acceptable cosmetic outcomes. This study describes the evaluation of early outcomes of a combined cosmetic assessment programme following breast conservation surgery.

\section{Materials and Methods}

An ethically approved prospective study was conducted at Letterkenny Univer- 
sity Hospital and a 15 month timeframe was chosen. All consecutive patients undergoing conservative breast surgery with complete local excision from July 2015 to October 2016 were entered into the study. Written consent was obtained from all patients. Patients undergoing mastectomy and reconstruction with either implant or autologous tissue were not included. Complete local excisions were performed by a single breast surgeon (MS). Generally internal advancement flap and breast plate defect closure were obtained in all patients [19]. Drains to the breast were not used. Skin was closed with subcutaneous suture. Antibiotic prophylaxis was used in all and cavity marked with clips. All patients were discussed at multidisciplinary meetings and external whole breast radiotherapy planned appropriately. Axillary surgery was undertaken according to the Unit's protocol, with clinically and ultrasonographically negative nodes undergoing sentinel node biopsy with patent blue [20]. Radiotherapy boost were recommended for close $(<2 \mathrm{~mm})$ radial margins and where anterior or posterior margins were involved.

Cosmetic evaluations were carried out by a combination of objective and subjective assessment methods. Objective assessment of cosmetic outcome used the Breast Cancer Conservative Treatment-cosmetic results [BCCT.core 2.0 Software ${ }^{\ddagger}$ [ [21]. BCCT.core software assesses a standardised anterior-posterior digital photograph and compares treated and untreated breasts for a number of key factors including; asymmetry of size, shape, colour differences and scars and gives an overall score of excellent, good, fair or poor. Each of these responses has a value of between 1 and 4 with a higher rating reflecting a poorer outcome.

Standardized protocol for photography was employed. A mid blue seamless photographic background paper with a non-reflective surface formed the backdrop and a Nikon D5000 digital camera was used without a flash. Consistent room lighting conditions, digital program mode settings and high quality image file format were applied. Following informed written consent all jewellery and clothing from waist up was removed. An " $\mathrm{X}$ " was placed on the sternal notch and another $25 \mathrm{cms}$ below this to enable the Software to calculate correctly. Photographs were taken from four standard views: from front with hands on hips; from front with hands raised above head; left lateral with hands raised above head and right lateral with hands raised above head (Figure 1).

Photographic assessments were carried out pre-operatively and 10 - 14 days post-surgery. Short term follow-up photography planned for all patients at one year post surgery to assess effect of retraction and radiotherapy will be reported in a future manuscript. For those participants requiring re-excision the second set of photographs were taken 10 - 14 days post re-excision surgery. BCCT.core Software analyses only the anterior-posterior (hands on hips) photograph.

Panel assessment of all 4 photographic views was undertaken by external experts in breast surgery. The panel consisted of experienced consultants in breast, oncoplastic and plastic surgery each with over 10 years' experience in specialist breast practice. The Harvard Scale [22] was used to grade results, defining an 
excellent cosmetic outcome when the treated breast is nearly identical to the untreated breast; a good cosmetic outcome when the treated breast is slightly different than the untreated; a fair cosmetic outcome when the treated breast is clearly different from the untreated but not seriously distorted and poor when the treated breast is seriously distorted. Each of these responses has a value of between 1 and 4 with a higher rating reflecting a poorer outcome.
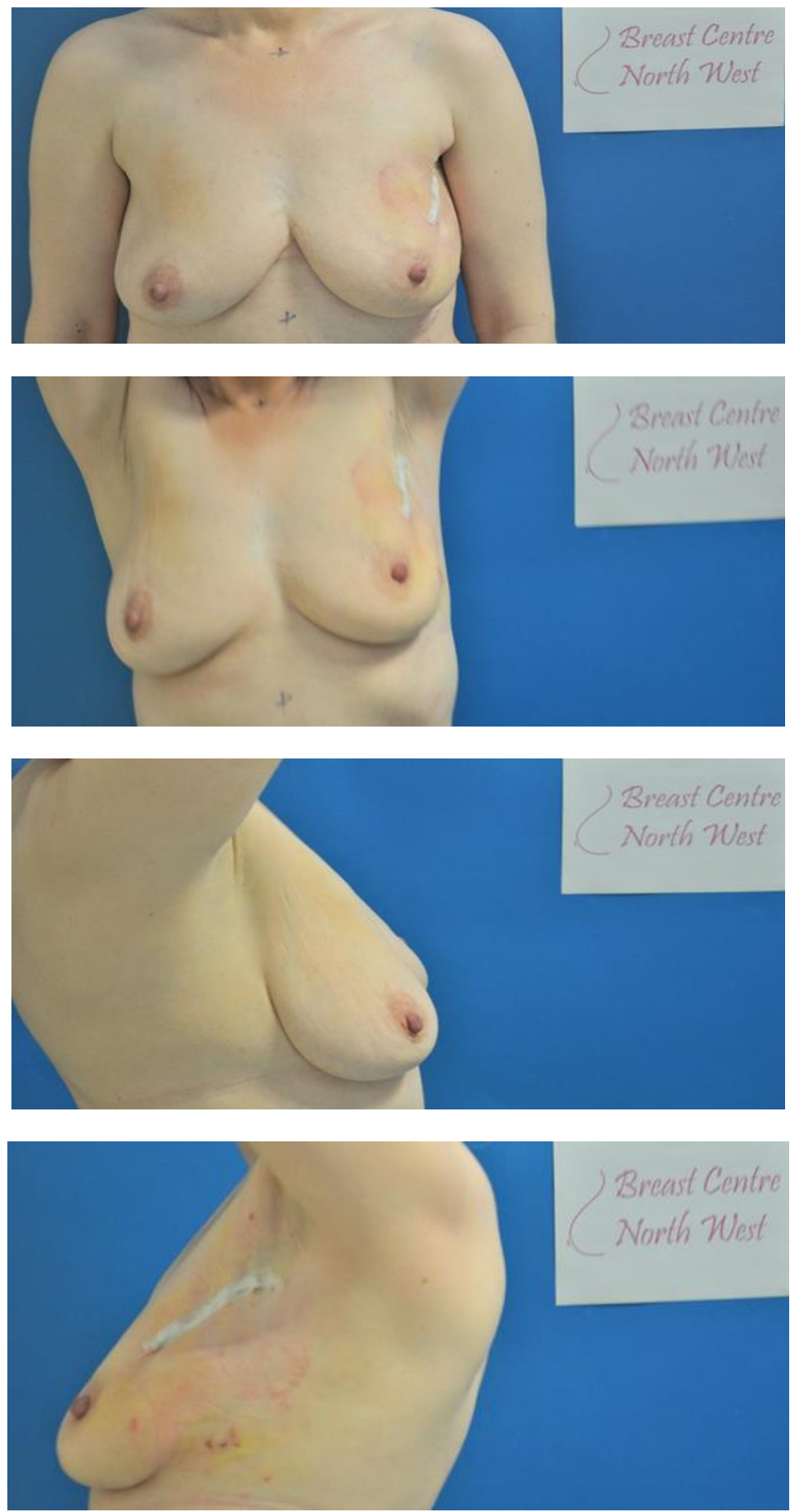

Figure 1. Standardised photographic views. 
Patient Reported Outcomes (PROs) evaluation was carried out using the internationally validated Breast Cancer Treatment Outcome Scale (BCTOS). A total of eighteen questions were asked each with a factor loading $\geq 0.42$ to one of the three subscales of cosmesis, functionality or breast pain [23]. Patients were asked to rate each item to evaluate the difference between the treated and untreated breast and surrounding areas. Each of the responses scored from 1 and 4 with a higher rating reflecting a poorer outcome. The overall rating for each of the 3 subscales was calculated as the mean of the ratings for all the items belonging to that subscale [16] [24]. If a response highlighted any difference then the participant was asked if this difference was of a concern to them. BCTOS assessments were carried out 10 - 14 days post surgery.

Pre-operative breast volume was calculated using the Digital Breast Volume Estimation method (DBVE) [25]. Demographic and pathological data, breast excision weight, percentage breast volume excised (BVE) (using the formula total resection volume/breast volume $\times 100$ ), margin positivity, complications and re-excision were prospectively documented.

Data was expressed as mean and standard deviation for normally distributed data and medians and inter quartile range for non-normal data. The scores for each assessment method were also dichotomised to excellent/good and fair/poor and results analysed. Interclass Correlation and Fleiss' Kappa were used to evaluate inter-rater agreement in the panel assessment.

${ }^{\ddagger}$ BCCT.core 2.0 Software. (INESC Porto Breast Research Group (Portugal).

\section{Results}

The demographic and clinical characteristics in the 41 consecutive patients are summarized in Table 1.

The mean breast volume was $768.3 \mathrm{~cm}^{3} \pm 440$ (range 200 - 1964), breast volume excised weighed $78.6 \mathrm{~g} \pm 42.6$ (18.9 - 214.4) and mean percentage of breast volume excised was $11.3 \% \pm 5.2 \%(5.1-23.3)$. 19/41 (46.3\%) had one surgical incision site and 22/41 (53.7\%) had two in order to obtain axillary nodal tissue. $6 / 41$ (14.6\%) had no nodal surgery. The re-excision rate was $2 / 41$ (4.9\%) all for positive margins. No wound infections or haematomas occurred.

The PROs, BCCT.core and Expert Panel evaluations of the cosmetic status 10 - 14 days post surgery are shown in Table 2.

A comparison of the dichotomised scores is presented in Table 3.

Expert panel scoring approach found that in 66/164 (40.2\%) the treated breast was nearly identical to untreated breast, slightly different than untreated in $70 / 164(42.7 \%)$, clearly different from untreated but not seriously distorted in $26 / 164(15.9 \%)$ and a seriously distorted in $2 / 164$ (1.2\%). The interclass correlation score was 0.39 (range 0.23 - 0.56) indicating moderate agreement. The mean average intraclass correlation was 0.72 (range $0.54-0.84$ ). The weighted average Kappa measured 0.16 and p-value 0.0005. Figure 2 shows how the panel scores correlated with the BCTOS and BCCT.core cosmetic evaluations. 
PROs using BCTOS questionnaire identified no change in breast shape in $19 / 41$ (46.3\%), a slight change in $16 / 41$ (39\%), moderate in $6 / 41$ (14.6\%) and large in $0 / 41(0 \%)$.

Objective analysis of cosmetic outcome by BCCT.core Software identified the overall cosmetic result as being excellent in $0 / 41$ (0\%), good $32 / 41$ (78\%), fair 9/41 (22\%) and poor 0/41 (0\%).

Patient Reported Outcomes of functional status from the BCTOS were (mean \pm sd) $1.5 \pm 0.8$ and breast specific pain $1.8 \pm 0.8$. The dichotomised scores are presented in Table 4. Cosmetic concerns were reported by 4/41 (9.8\%) and these were size of breast, texture of breast, nipple appearance and fit of bra. No functional or breast specific pain concerns were reported.

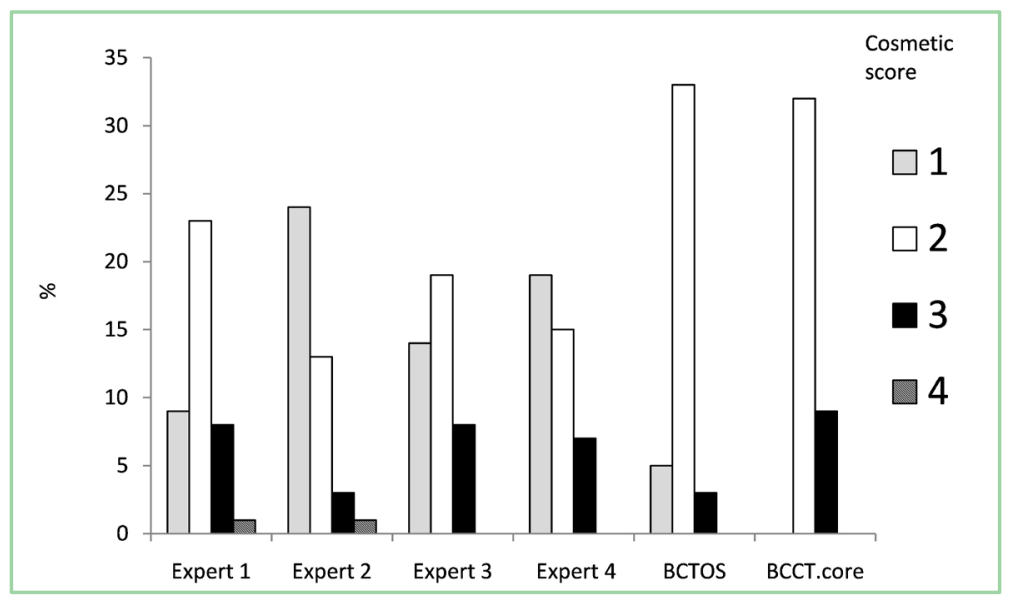

Figure 2. Cosmetic assessment outcome scores post surgery.

Table 1. The demographic and clinical characteristics of the study population $(n=41)$.

\begin{tabular}{|c|c|c|c|c|}
\hline & Mean & SD & & Range \\
\hline Age & 55 & 13 & & $36-80$ \\
\hline BMI $\left(\mathrm{kg} / \mathrm{m}^{2)}\right.$ & 25.3 & 3.7 & & $18.6-36.1$ \\
\hline \multirow[t]{2}{*}{ Tumour size (mm) } & 19.7 & 12.8 & & $2.4-60$ \\
\hline & $\mathrm{n}$ & & $\%$ & \\
\hline \multicolumn{5}{|c|}{ Tumour type: } \\
\hline In-situ & 7 & & 17.1 & \\
\hline Invasive & 34 & & 82.9 & \\
\hline \multicolumn{5}{|c|}{ Tumour grade (in $\mathrm{n}=34$ invasive): } \\
\hline G1 & 8 & & 23.5 & \\
\hline G2 & 13 & & 38.2 & \\
\hline G3 & 13 & & 38.2 & \\
\hline G3-triple negative & 10 & & 76.9 & \\
\hline \multicolumn{5}{|c|}{ Nodal status: } \\
\hline Negative & 29 & & 70.7 & \\
\hline Positive & 12 & & 29.3 & \\
\hline
\end{tabular}




\section{Continued}

\begin{tabular}{ccc}
\hline Tumour stage: & & \\
Tis & 7 & 17 \\
I & 15 & 36.6 \\
II & 17 & 41.5 \\
III & 2 & 4.9 \\
IV & 0 & 0 \\
\hline
\end{tabular}

Table 2. Patient Reported Outcomes (BCTOS), BCCT.core and Expert Panel assessments of cosmetic status 10 - 14 days post surgery.

\begin{tabular}{ccc}
\hline Cosmetic Status & No. & Mean \pm sd \\
\hline BCTOS & 41 & $1.5 \pm 0.7$ \\
BCCT.core & 41 & $2.2 \pm 0.4$ \\
Expert Panel (mean) & 41 & $1.8 \pm 0.7$ \\
Expert 1 & 41 & $2.0 \pm 0.7$ \\
Expert 2 & 41 & $1.5 \pm 0.7$ \\
Expert 3 & 41 & $1.9 \pm 0.7$ \\
Expert 4 & 41 & $1.7 \pm 0.7$ \\
\hline
\end{tabular}

Table 3. Patient Reported Outcomes (BCTOS), BCCT.core and Expert Panel assessments of cosmetic status 10 - 14 days post surgery-comparison of dichotomised scores.

\begin{tabular}{cccc}
\hline \multirow{2}{*}{ Cosmetic status } & Overall No. & \multicolumn{2}{c}{ Excellent or good outcome* } \\
\cline { 3 - 4 } & & No. $(\%)$ & No. $(\%)$ \\
\hline BCTOS & 41 & $38(92.7)$ & $3(7.3)$ \\
BCCT.core & 41 & $32(78.0)$ & $9(22)$ \\
Expert Panel (mean) & 41 & $136(82.9)$ & $28(17.1)$ \\
Expert 1 & 41 & $32(78.0)$ & $9(22)$ \\
Expert 2 & 41 & $37(90.2)$ & $4(9.8)$ \\
Expert 3 & 41 & $33(80.5)$ & $8(19.5)$ \\
Expert 4 & 41 & $34(82.9)$ & $7(17.1)$ \\
\hline
\end{tabular}

${ }^{*}$ Excellent or good $=\mathrm{a}$ response value of either 1 or $2,{ }^{* *}$ Fair or poor $=$ a response value of either 3 or 4.

Table 4. Patient Reported Outcomes of functional status and breast specific pain $10-14$ days post surgery-dichotomised scores.

\begin{tabular}{cccc}
\hline & & Excellent or good outcome & Fair or poor outcome \\
\hline $\begin{array}{c}\text { Measure } \\
\text { Functional } \\
\text { status-BCTOS }\end{array}$ & Overall No. & No. (\%) & No. (\%) \\
$\begin{array}{c}\text { Breast specific } \\
\text { pain-BCTOS }\end{array}$ & 41 & $36(87.8)$ & $5(12.1)$ \\
\hline
\end{tabular}

* Excellent or good $=$ a response value of either 1 or $2,{ }^{* *}$ Fair or poor $=$ a response value of either 3 or 4. 


\section{Discussion}

This study successfully prospectively evaluated objective and subjective related outcomes following breast conserving surgery. It incorporated both patient and surgeon in these early outcomes assessment. The results were encouraging showing that despite low re-excision rates acceptable cosmetic outcomes were achieved.

Breast conserving surgery oncological outcomes are as good as or higher than mastectomy, when combined with multidisciplinary care and appropriate adjuvant therapies [4] [5] [6] [7]. A clear margin, with no tumour on ink is an important goal from the index operation. Achieving this can be difficult and margin positive rates are on average $25 \%$, with re-excision approaching $20 \%$ [10] [11]. These rates are unacceptable and may relate in part to the surgeons fear of excising excessive tissue volume and its impact on form, functions and patient perceptions [26]. While the concept of the ideal breast shape has been reported, obtaining patients perceptions of their breast before and after conservative breast surgery suggests that the majority are happy with outcomes [27] [28]. What is not clear however is the cosmetic outcomes where margin positivity and re-excision is low.

There have been a number of studies looking at breast and tumour dimension. Concepts of ideal breast volume excision and breast volume to tumour resections ratios are important in the aesthetic outcomes [8] [29]. Surgery and cosmetic outcomes coupled with a cancer diagnosis exert a significant psychological impact on patients [30] [31].

Standardising cosmetic evaluation is difficult following breast conserving surgery [18]. Many factors affect outcomes including tumour size, incision site, location on breast, cup size, BMI, volume of breast tissue excised, complications and need for adjuvant therapy [16] [32] [33]. Functional factors such as pain and tissue oedema may exert a negative influence on outcomes [34] [35]. Radiotherapy's effect will be influenced by the number of fields, volume of breast treated, dose given and when given concomitantly with chemotherapy [36] [37].

Accurate assessment of breast volume is challenging with no gold standard currently available [24] [38]. Current methods of volume calculation exhibit variable reliability; many require a level of detail that is difficult to reproduce, are impractical, are often not cost effective or may not be acceptable to the patient [39]. DBVE involves digital mapping of mammograms to calculate breast area with subsequent mathematical calculations using breast compression measurements to calculate breast volume [25].

There is currently no gold standard cosmetic assessment tool. BCCT core software was used in this study as it is simple, feasible, objective and suited to the Caucasian study population [21] [40] [41] [42]. The software may need refinement when used to evaluate the cosmetic outcome of an Asian population [43]. Photography has been widely used, with some studies evaluating 5 views [14].

Generally, the surgical approach used in this study was an internal advanced 
flap and breast plate defect closure. Hennigs and colleagues (2016) found that the surgical approaches which correlated with a negative cosmetic outcome included radial, fish-mouth and periareolar while other studies found no significant differences for overall body image scores when comparing anterior to lateral approaches [33] [44]. Nipple position and distance to nipple from inframammary fold are two of the measures of symmetry used in BCCT.core. Patients' opinions on cosmetic outcome were also significantly related to objective parameters like distance from nipple to inframammary fold [45]. Vrieling and colleagues however found nipple position to be only moderately representative of the overall cosmetic outcomes [46].

With advances in earlier diagnosis and treatment advances, long term survival and the accompanying sequelae such as cosmetic and functioning outcomes are gaining greater importance. Advances in operative technology may help improve cosmetic outcomes. Intraoperative ultrasound (IUS) guidance in breast conserving surgery reduced the chances of a worse cosmetic outcome by $47 \%$ compared to palpation guided surgery in a study by Volders and colleagues (2017) [31]. Haloua (2016) also found improvement in cosmetic outcome and patient satisfaction using IUS in breast conserving surgery [17].

Breast Q developed by Pusic and colleagues (2009) is thorough but time consuming [47]. We have reviewed our outcomes after mastectomy and reconstruction but this is the first attempt after complete local excisions [48]. Both Cardosa and Merie have advocated for standardization of breast outcome assessment [17] [42]. Evaluation of outcome has been difficult with suggestions that a dichotomized grading is superior to a categorical approach, improving consensus among reviewers [49]. Merie recently found in a large long term follow-up study of patients' outcomes following conservative surgery and radiotherapy that using both BCCT.core assessment and patient self-assessment could form the benchmark tool [17]. Merie interestingly did not include plastic and reconstructive surgeons in their analysis. This study found moderate agreement between reviewers.

Panel assessment is superior to a single evaluation [50]. The question remains should the ideal number of the panel be perhaps two so long as they are not the operating surgeon. The Harris Scale, a global aesthetic assessment Likert scale, is still one of the most widely used measures in panel assessments of cosmetic outcome following breast surgery; despite having several drawbacks it has the advantage that it is easier to use [22] [51].

Follow-up assessment is planned for all patients at one year post surgery. Hennigs and colleagues found that patients reporting poor cosmetic outcome postoperatively were likely to remain unsatisfied with outcome over time [33]. The cosmetic outcomes at one year appear to be representative of long term cosmetic outcome after BCT [31].

Physician-patient relationships benefit by active enrolment in health care outcome studies as well as improving patients' HRQoL and emotional functioning [52]. 
This study is relatively small in numbers and only includes one surgeon's patients. While it has been validated externally it deals only with early cosmetic and functional outcomes, before administration of radiotherapy.

\section{Conclusion}

This study developed a robust outcomes assessment tool. Incorporation in routine breast practice may not only provide great understanding of outcomes, but combine the patients and the physician assessment.

\section{Conflicts of Interest}

The authors declare no conflicts of interest regarding the publication of this paper.

\section{References}

[1] Howell, D., Molloy, S., Wilkinson, K., et al. (2015) Patient-Reported Outcomes in Routine Cancer Clinical Practice: A Scoping Review of Use, Impact on Health Outcomes, and Implementation Factors. Annals of Oncology, 26, 1846-1858. https://doi.org/10.1093/annonc/mdv181

[2] Basch, E. (2017) The Rise of Patient-Reported Outcomes in Oncology. In ASCO Annual Meeting. https://am.asco.org/daily-news/rise-patient-reported-outcomes-oncology

[3] Bride, M.B., Neal, L., Dilaveri, C.A., et al. (2013) Factors Associated with Surgical Decision Making in Women with Early-Stage Breast Cancer: A Literature Review. Journal of Women's Health, 22, 236-242. https://doi.org/10.1089/jwh.2012.3969

[4] Fisher, B., Anderson, S., Bryant, J., et al. (2002) Twenty-Year Follow-Up of a Randomized Trial Comparing Total Mastectomy, Lumpectomy, and Lumpectomy plus Irradiation for the Treatment of Invasive Breast Cancer. The New England Journal of Medicine, 347, 1233-1241. https://doi.org/10.1056/NEJMoa022152

[5] Veronesi, U., Cascinelli, N., Mariani, L., et al. (2002) Twenty-Year Follow-Up of a Randomized Study Comparing Breast-Conserving Surgery with Radical Mastectomy for Early Breast Cancer. The New England Journal of Medicine, 347, 1227-1232. https://doi.org/10.1056/NEJMoa020989

[6] Livingston, E.H. and Li, H.C. (2017) Breast Cancer Surgery: Less Is More. JAMA, 318, 909-911. https://doi.org/10.1001/jama.2017.12890

[7] Agarwal, S., Pappas, L., Neumayer, L., et al. (2014) Effect of Breast Conservation Therapy vs Mastectomy on Disease-Specific Survival for Early-Stage Breast Cancer. JAMA Surgery, 149, 267-274. https://doi.org/10.1001/jamasurg.2013.3049

[8] Krekel, N., Zonderhuis, B., Muller, S., et al. (2011) Excessive Resections in Breast-Conserving Surgery: A Retrospective Multicentre Study. The Breast Journal, 17, 602-609. https://doi.org/10.1111/j.1524-4741.2011.01198.x

[9] Haloua, M.H., Volders, J.H., Krekel, N.M., et al. (2016) A Nationwide Pathology Study on Surgical Margins and Excision Volumes after Breast-Conserving Surgery: There Is Still Much to Be Gained. Breast, 25, 14-21. https://doi.org/10.1016/j.breast.2015.11.003

[10] Hayashi, N., Tsunoda, H., Abe, E., et al. (2012) Ultrasonography-and/or Mammography-Guided Breast Conserving Surgery for Ductal Carcinoma in Situ of the Breast: Experience with 87 Lesions. Breast Cancer, 19, 131-137. 
https://doi.org/10.1007/s12282-010-0218-5

[11] Unzeitig, A., Kobbermann, A., Xie, X.J., et al. (2012) Influence of Surgical Technique on Mastectomy and Re-Excision Rates in Breast-Conserving Therapy for Cancer. International Journal of Surgical Oncology, 2012, Article ID: 725151.

[12] Saolta University Health Care Group. (2015) Symptomatic Breast Service Annual Report. Health Service Executive.

http://www.saolta.ie/sites/default/files/publications/Symptomatic\%20\%20Breast $\% 20$ Service\%20Annual\%20Report\%202015.pdf

[13] Beecher, S.M., O’Leary, D.P., McLaughlin, R., et al. (2016) Influence of Complications Following Immediate Breast Reconstruction on Breast Cancer Recurrence Rates. British Journal of Surgery, 103, 391-398. https://doi.org/10.1002/bjs.10068

[14] Racz, J.M., Hong, N.L. and Latosinsky, S. (2015) In Search of a Gold Standard Scoring System for the Subjective Evaluation of Cosmetic Outcomes Following Breast-Conserving Therapy. The Breast Journal, 21, 345-351. https://doi.org/10.1111/tbj.12423

[15] Landercasper, J., Attai, D., Atisha, D., et al. (2015) Toolbox to Reduce Lumpectomy Reoperations and Improve Cosmetic Outcome in Breast Cancer Patients: The American Society of Breast Surgeons Consensus Conference. Annals of Surgical Oncology, 22, 3174-3183. https://doi.org/10.1245/s10434-015-4759-x

[16] Pukancsik, D., Kelemen, P., Újhelyi, M., et al. (2017) Objective Decision Making between Conventional and Oncoplastic Breast-Conserving Surgery or Mastectomy: An Aesthetic and Functional Prospective Cohort Study. EJSO, 43, 303-310. https://doi.org/10.1016/j.ejso.2016.11.010

[17] Merie, E., Browne, L., Cardoso, J., et al. (2017) Proposal for a Gold Standard for Cosmetic Evaluation after Breast Conserving Therapy: Results from the St George and Wollongong Breast Boost Trial. Journal of Medical Imaging and Radiation Oncology, 61, 819-825. https://doi.org/10.1111/1754-9485.12645

[18] Oliveira, H.P., Cardoso, J.S., Magalhães, A., et al. (2013) Methods for the Aesthetic Evaluation of Breast Cancer Conservation Treatment: A Technological Review. Current Medical Imaging Reviews, 9, 32-46. https://doi.org/10.2174/1573405611309010006

[19] Shaikh, T., Narra, V., Goyal, S., et al. (2013) Lumpectomy Closure Technique Does Not Affect Dosimetry in Patients Undergoing External-Beam-Based Accelerated Partial Breast Irradiation. Annals of Surgical Oncology, 20, 1323-1328. https://doi.org/10.1245/s10434-012-2775-7

[20] Ting, G., McGowan, K., Cooley, G., et al. (2015) The Role of Ultrasound Guided Core Biopsy of Axillary Nodes in Predicting Macrometastases and Avoiding Overtreatment outside ACOSOG Z0011 Parameters. Breast, 24, 57-61.

https://doi.org/10.1016/j.breast.2014.11.007

[21] Cardoso, M.J., Cardoso, J., Amaral, N., et al. (2007) Turning Subjective into Objective: The BCCT.core Software for Evaluation of Cosmetic Results in Breast Cancer Conservative Treatment. Breast, 16, 456-461. https://doi.org/10.1016/j.breast.2007.05.002

[22] Harris, J.R., Levene, M.B., Svensson, G., et al. (1979) Analysis of Cosmetic Results Following Primary Radiation Therapy for Stages I and II Carcinoma of the Breast. International Journal of Radiation Oncology, Biology, Physics, 5, 257-261. https://doi.org/10.1016/0360-3016(79)90729-6

[23] Stanton, A.L., Krishnan, L. and Collins, C.A. (2001) Form or Function? Part 1. Subjective Cosmetic and Functional Correlates of Quality of Life in Women Treated 
with Breast-Conserving Surgical Procedures and Radiotherapy. Cancer, 91, 2273-2281.

https://doi.org/10.1002/1097-0142(20010615)91:12<2273::AID-CNCR1258>3.0.CO; $\underline{2-1}$

[24] Heil, J., Dahlkamp, J., Golatta, M., et al. (2011) Aesthetics in Breast Conserving Therapy: Do Objectively Measured Results Match Patients' Evaluations? Annals of Surgical Oncology, 18, 134-138. https://doi.org/10.1245/s10434-010-1252-4

[25] Shanley, E., Johnston, A., Hillick, D., Ng, K.C. and Sugrue, M. (2018) Digital Breast Volume Estimation (DBVE)-A New Technique. The British Journal of Radiology, 91. https://doi.org/10.1259/bjr.20180406

[26] Boughey, J.C., Hieken, T.J., Jakub, J.W., et al. (2014) Impact of Analysis of Frozen-Section Margin on Reoperation Rates in Women Undergoing Lumpectomy for Breast Cancer: Evaluation of the National Surgical Quality Improvement Program Data. Surgery, 156, 190-197. https://doi.org/10.1016/j.surg.2014.03.025

[27] Mallucci, P. and Branford, O.A. (2012) Concepts in Aesthetic Breast Dimensions: Analysis of the Ideal Breast. Journal of Plastic, Reconstructive \& Aesthetic Surgery, 65, 8-16. https://doi.org/10.1016/j.bjps.2011.08.006

[28] Ojala, K., Meretoja, T.J. and Leidenius, M.H. (2017) Aesthetic and Functional Outcome after Breast Conserving Surgery-Comparison between Conventional and Oncoplastic Resection. European Journal of Surgical Oncology, 43, 658-664. https://doi.org/10.1016/j.ejso.2016.11.019

[29] Vos, E.L., Koning, A.H., Obdeijn, I.M., et al. (2015) Preoperative Prediction of Cosmetic Results in Breast Conserving Surgery. Journal of Surgical Oncology, 111, 178-184. https://doi.org/10.1002/jso.23782

[30] Nano, M.T., Gill, P.G., Kollias, J., Bochner, M.A., et al. (2005) Psychological Impact and Cosmetic Outcome of Surgical Breast Cancer Strategies. ANZ Journal of Surgery, 75, 940-947. https://doi.org/10.1111/j.1445-2197.2005.03517.x

[31] Volders, J.H., Negenborn, V.L., Haloua, M.H., et al. (2017) Cosmetic Outcome and Quality of Life Are Inextricably Linked in Breast-Conserving Therapy. Journal of Surgical Oncology, 115, 941-948. https://doi.org/10.1002/jso.24615

[32] Hennigs, A., Hartmann, B. and Rauch, G. (2015) Long-Term Objective Esthetic Outcome after Breast-Conserving Therapy. Breast Cancer Research and Treatment, 153, 345-351. https://doi.org/10.1007/s10549-015-3540-y

[33] Hennigs, A., Biehl, H., Rauch, G., et al. (2016) Change of Patient-Reported Aesthetic Outcome over Time and Identification of Factors Characterizing Poor Aesthetic Outcome after Breast-Conserving Therapy: Long-Term Results of a Prospective Cohort Study. Annals of Surgical Oncology, 23, 1744-1751.

https://doi.org/10.1245/s10434-015-4943-z

[34] Kopec, J.A., Colangelo, L.H., Land, S.R., et al. (2013) Relationship between Arm Morbidity and Patient-Reported Outcomes Following Surgery in Women with Node-Negative Breast Cancer: NSABP Protocol B-32. Journal of Surgical Oncology, $11,22$.

[35] Patterson, M.P., Pezner, R.D., Hill, L.R., et al. (1985) Patient Self-Evaluation of Cosmetic Outcome of Breast-Preserving Cancer Treatment. International Journal of Radiation Oncology, Biology, Physics, 11, 1849-5182. https://doi.org/10.1016/0360-3016(85)90044-6

[36] Key, S., Miglierini, P., Dupré, P.F., et al. (2017) Cosmetic Outcome and Chronic Breast Toxicity after Intraoperative Radiation Therapy (IORT) as a Single Modality or as a Boost Using the Intrabeam ${ }^{\circledast}$ Device: A Prospective Study. Annals of Surgical 
Oncology, 24, 2547-2555. https://doi.org/10.1245/s10434-017-5920-5

[37] Taylor, M.E., Perez, C.A., Halverson, K.J., et al. (1995) Factors Influencing Cosmetic Results after Conservation Therapy for Breast Cancer. International Journal of Radiation Oncology, Biology, Physics, 31, 753-764. https://doi.org/10.1016/0360-3016(94)00480-3

[38] Yip, J.M., Mouratova, N., Jeffery, R.M., et al. (2012) Accurate Assessment of Breast Volume: A Study Comparing the Volumetric Gold Standard (Direct Water Displacement Measurement of Mastectomy Specimen) with a 3D Laser Scanning Technique. Annals of Plastic Surgery, 68, 135-141. https://doi.org/10.1097/SAP.0b013e31820ebdd0

[39] Kayar, R., Civelek, S., Cobanoglu, M., et al. (2011) Five Methods of Breast Volume Measurement: A Comparative Study of Measurements of Specimen Volume in 30 Mastectomy Cases. Breast Cancer. Basic and Clinical Research, 5, 43-52. https://doi.org/10.4137/BCBCR.S6128

[40] Yu, T., Eom, K.Y., Jang, N.Y., et al. (2016) Objective Measurement of Cosmetic Outcomes of Breast Conserving Therapy Using BCCT.core. Cancer Research and Treatment, 48, 491-498. https://doi.org/10.4143/crt.2015.088

[41] Dahlbäck, C., Ullmark, J.H., Rehn, M., et al. (2017) Aesthetic Result after Breast-Conserving Therapy Is Associated with Quality of Life Several Years after Treatment. Swedish Women Evaluated with BCCT.core and BREAST-Q ${ }^{\mathrm{Tm}}$. Breast Cancer Research and Treatment, 23, 1-9. https://doi.org/10.1007/s10549-017-4306-5

[42] Cardoso, M.J., Cardoso, J.S., Vrieling, C., et al. (2012) Recommendations for the Aesthetic Evaluation of Breast Cancer Conservative Treatment. Breast Cancer Research and Treatment, 135, 629-637. https://doi.org/10.1007/s10549-012-1978-8

[43] Nohara, Y., Hanamura, N., Zaha, H., et al. (2015) Cosmetic Evaluation Methods Adapted to Asian Patients after Breast-Conserving Surgery and Examination of the Necessarily Elements for Cosmetic Evaluation. Journal of Breast Cancer, 18, 80-86. https://doi.org/10.4048/jbc.2015.18.1.80

[44] Lee, M., Patel, M., Cresswell, A.B., et al. (2007) Body Image Score Following Anterior and Lateral Approaches to Wide Local Excision for Early Breast Cancer. The Breast Journal, 13, 238-242. https://doi.org/10.1111/j.1524-4741.2007.00416.x

[45] Brouwers, P., Van Werkhoven, E., Van Loon, J., et al. (2016) PO-0674: Factors Influencing Patient Reported Cosmetic Outcome: Results of the Young Boost Trial. Radiotherapy and Oncology, 119, S314-S315. https://doi.org/10.1016/S0167-8140(16)31924-7

[46] Vrieling, C., Collette, L., Fourquet, A., et al. (2000) The Influence of Patient, Tumor and Treatment Factors on the Cosmetic Results after Breast-Conserving Therapy in the EORTC “Boost vs. No Boost” Trial. Radiotherapy and Oncology, 55, 219-232. https://doi.org/10.1016/S0167-8140(00)00210-3

[47] Pusic, A.L., Klassen, A.F., Scott, A.M., et al. (2009) Development of a New Patient-Reported Outcome Measure for Breast Surgery: The BREAST-Q. Plastic and Reconstructive Surgery, 124, 345-353. https://doi.org/10.1097/PRS.0b013e3181aee807

[48] Sugrue, R., MacGregor, G., Sugrue, M., et al. (2013) An Evaluation of Patient Reported Outcomes Following Breast Reconstruction Utilizing Breast Q. Breast, 22, 158-161. https://doi.org/10.1016/j.breast.2012.12.001

[49] Pezner, R.D., Lipsett, J.A., Vora, N.L., et al. (1985) Limited Usefulness of Observer-Based Cosmesis Scales Employed to Evaluate Patients Treated Conservatively 
for Breast Cancer. International Journal of Radiation Oncology, Biology, Physics, 11, 1117-1119. https://doi.org/10.1016/0360-3016(85)90058-6

[50] Fortin, A.J., Cheang, M. and Latosinsky, S. (2006) Cosmetic Outcomes Following Breast Conservation Therapy: In Search of a Reliable Scale. Breast Cancer Research and Treatment, 100, 65-70. https://doi.org/10.1007/s10549-006-9223-y

[51] Kim, K.D., Kim, Z., Kuk, J.C., et al. (2016) Long-Term Results of Oncoplastic Breast Surgery with Latissimus Dorsi Flap Reconstruction: A Pilot Study of the Objective Cosmetic Results and Patient Reported Outcome. Annals of Surgical Treatment and Research, 90, 117-123. https://doi.org/10.4174/astr.2016.90.3.117

[52] Velikova, G., Booth, L., Smith, A.B., et al. (2004) Measuring Quality of Life in Routine Oncology Practice Improves Communication and Patient Well-Being: A Randomized Controlled Trial. Journal of Clinical Oncology, 22, 714-724.

https://doi.org/10.1200/JCO.2004.06.078 